\title{
Towards measuring the meridional overturning circulation from
}

\section{space}

\author{
D. Cromwell ${ }^{1}$, A. G. P. Shaw ${ }^{1}$, P. Challenor ${ }^{1}$, R. E. Houseago-Stokes ${ }^{1}$, and R. Tokmakian ${ }^{2}$ \\ ${ }^{1}$ Ocean Observations and Climate, National Oceanography Centre, Southampton (NOCS), UK \\ ${ }^{2}$ Naval Postgraduate School, Monterey, California, USA
}

Received: 20 September 2006 - Published in Ocean Sci. Discuss.: 6 October 2006

Revised: 7 February 2007 - Accepted: 26 April 2007 - Published: 14 May 2007

\begin{abstract}
We present a step towards measuring the meridional overturning circulation (MOC), i.e. the full-depth water mass transport, in the North Atlantic using satellite data. Using the Parallel Ocean Climate Model, we simulate satellite observations of ocean bottom pressure and sea surface height (SSH) over the 20-year period from 1979-1998, and use a linear model to estimate the MOC. As much as $93.5 \%$ of the variability in the smoothed transport is thereby explained. This increases to $98 \%$ when SSH and bottom pressure are first smoothed. We present initial studies of predicting the time evolution of the MOC, with promising results. It should be stressed that this is an initial step only, and that to produce an actual working system for measuring the MOC from space would require considerable future work.
\end{abstract}

\section{Introduction}

Heat transported northwards in the Atlantic by the thermohaline circulation (THC) produces a warmer climate in Western Europe than would otherwise be the case. Modelling studies suggest that, under global warming, the THC will slow down or even shut off (e.g. Rahmstorf and Ganopolski, 1999; Wood et al., 1999; Stocker et al., 2001; Gregory et al., 2005).

Some studies suggest that a slowdown of the North Atlantic THC might already be occurring (Häkkinen, 2001; Bryden et al., 2006). According to Häkkinen and Rhines (2004), in the last two decades there has been an increase in sea surface height (SSH) in the North Atlantic subpolar gyre and a reduction in the strength of the North Atlantic subpolar gyre in the 1990s. However, because of the lack of SSH data prior to 1978 , there is uncertainty as to whether this feature is a multidecadal cycle or a long-term trend. Levermann et al. (2005) used a coupled climate model to investi-

Correspondence to: D. Cromwell

(ddc@noc.soton.ac.uk) gate changes in SSH that would be expected as a result of a weakening of the THC: this would directly affect sea level through both warming of the global deep ocean and regional sea level changes associated with changing currents and mass distribution in the ocean. The study shows the usefulness of SSH measurements in observing the varying strength of the THC.

To detect the early onset of rapid climate change, the THC thus needs to be monitored. Separating the densitydriven THC (the thermal wind component of ocean circulation) from the wind-driven ocean circulation is impossible due to lack of data. However, measuring the THC by indirect methods is feasible. This can be achieved by using the meridional overturning circulation (MOC) as a proxy for the THC. The MOC is defined as the mass transport of water as a function of latitude and depth (e.g. Rahmstorf, 2006). As part of the UK Natural Environment Research Council's RAPID programme, an array has been deployed near $26^{\circ} \mathrm{N}$ to monitor the MOC from which measurements of temperature, salinity, currents and bottom pressure are obtained. Combining this information with satellite observations, cable measurements in the Florida Strait and ocean circulation models will enable a true 'observed' estimate of the MOC (Hirschi et al., 2003). An alternative strategy is to monitor the strength of the MOC from routine observations, including satellite data. We present the results of a feasibility study that adopts this latter approach. As we suggest in the conclusions, the two approaches could, in fact, complement each other. The Gravity Recovery And Climate Experiment (GRACE) satellite mission enables bottom pressure to be estimated monthly to an accuracy of $\sim 0.1$ mbar at a spatial resolution of $\sim 400 \mathrm{~km}$, and thus allows one to determine bottom pressure gradients (Tapley et al., 2003; 2004a, b). We could therefore, in principle, infer bottom velocity currents using GRACE (Wahr and Molenaar, 1998). Just two physical parameters, ocean bottom pressure and sea surface height, could effectively yield the total (i.e. the sum of the

Published by Copernicus GmbH on behalf of the European Geosciences Union. 


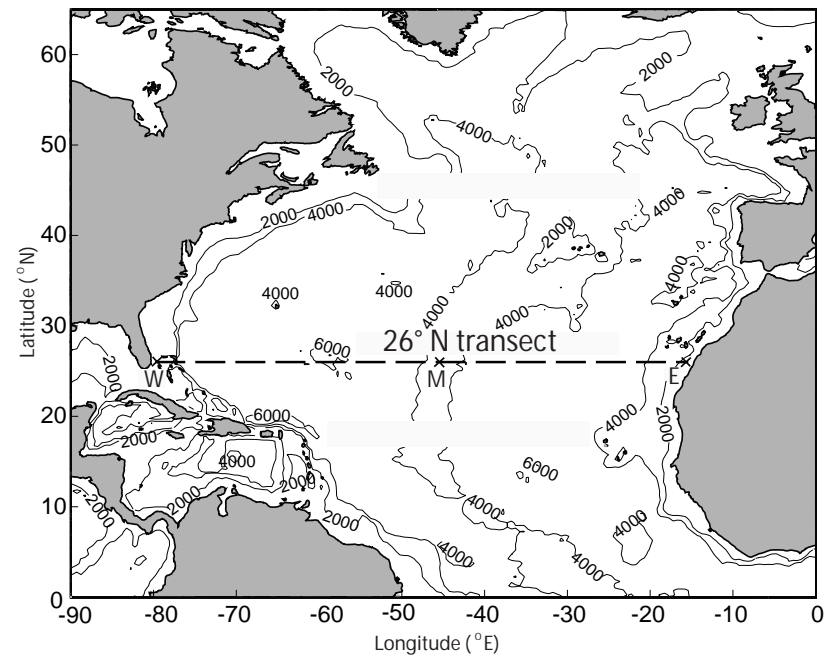

Fig. 1. The region of study in which model output was extracted from the Parallel Ocean Climate Model (POCM). Empirical orthogonal functions of sea surface height anomaly and bottom pressure anomaly were calculated for the two subregions north and south of the $26^{\circ} \mathrm{N}$ transect. The corresponding terms in Eqs. (5) and (6) are indicated by prefixes $N$ and $S$. In addition, the location of the three simulated in situ measurements on the $26^{\circ} \mathrm{N}$ transect, also extracted from POCM, are indicated by the prefixes $W, M$ and $E$.

barotropic and baroclinic components) geostrophic flow, and thus allow an estimate of the full-depth mass transport of the MOC.

As there are currently insufficient satellite-derived bottom pressure data, we simulate satellite observations of bottom pressure using the Parallel Ocean Climate Model (POCM). We do the same for SSH. The initial task, which is the topic of this paper, is to test how well the MOC could be estimated using satellite observations alone. The basic method is to use a linear model to predict the MOC from the simulated satellite observations of bottom pressure and SSH.

We emphasise that this paper is a feasibility study showing that it is possible to estimate the strength of the MOC from space; but it does not demonstrate an actual working system. It will take considerable follow-up work, and an improved resolution gravity mission, before such a system can be produced.

\section{Meridional overturning circulation}

\subsection{Introduction}

The MOC is defined as the mass transport of water as a function of latitude and depth. The MOC stream function, $\Psi$, is:

$\Psi\left(y, z_{0}, t\right)=\int_{-H}^{z_{0}} \int_{0}^{L} v(x, y, z, t) d x d z$ where $v=v(x, y, z, t)$ is the meridional velocity; $H=H(x, y)$ is the water depth; $L=L(y, z)$ is the zonal width of the basin; and $x, y, z$ and $t$ are the longitude, latitude, depth and time coordinates.

\subsection{Model description}

Our proposed method of monitoring the MOC is tested here using output from POCM-4C, a global eddy-permitting model (Semtner and Chervin, 1992). This is an established and realistic ocean model covering a multidecadal time period. Its MOC has average values of around $20 \mathrm{~Sv}$ (1 Sverdrup or $\mathrm{Sv}=10^{6} \mathrm{~m}^{3} / \mathrm{s}$ ), consistent with in situ observations (Marsh et al., 2005).

POCM is on a Mercator geographical grid with a longitudinal resolution of $0.4^{\circ}$ and a latitudinal resolution of $0.4^{\circ} \times \cos (\phi)$, where $\phi$ is latitude, yielding an average spatial resolution of $0.25^{\circ}$. The bottom topography is derived from the 5-minute of arc resolution grid of the Earth Topography dataset (ETOPO5). The model is forced with atmospheric fluxes (wind stress, freshwater and heat) using the European Centre for Medium-Range Weather Forecasts (ECMWF) twenty-year reanalysis (i.e., ERA-15 reanalysis product +5 years of consistent ECMWF operational fields processed with the same algorithms) data (Matano et al., 2002). The model run extends from Jan 1979 to Dec 1998, inclusive. The model was initialized from previous runs of the model (one 20-year simulation: see Stammer et al., 1996; and the initial $0.5^{\circ}$ simulation of Semtner and Chervin, 1992, with a spin-up of 33 years).

POCM has twenty depth levels, and a free surface consistent with the formulation of Killworth et al. (1991). A description of the POCM equations and algorithms can be found in Stammer et al. (1996). The geographical region from which POCM output is extracted here is $0^{\circ}$ to $68^{\circ} \mathrm{N}$, $0^{\circ}$ to $90^{\circ} \mathrm{W}$ (see Fig. 1). We use temperature, salinity, zonal $(u)$ and meridional $(v)$ velocities, as well as density.

To determine the realism of POCM, previous studies have compared the model with altimetry, hydrography and tide gauge observations (Stammer et al., 1996; Tokmakian, 1996; Tokmakian and Challenor, 1999). There was good agreement between POCM and hydrography at low latitudes of the Atlantic Ocean, where the rms difference was less than $7 \mathrm{~cm}$ (Stammer et al., 1996). The simulation of large-scale general circulation patterns was also realistic, although POCM generally had weak circulation on all scales. For example, the eddy kinetic energy was four times lower in the model compared with altimetry data (Stammer et al., 1996). Tokmakian (1996) compared a nine-year time series of POCM sea surface heights with tide gauge records and found that the model gave realistic local sea level variability.

It must be stressed here that the present paper is a feasibility study. Although, like all models, POCM is not a precise representation of the real ocean - notwithstanding that its MOC values in the North Atlantic are close to the observed 
strength - it does provide a useful test bed for developing the statistical methodology, which we now describe in the following section.

\section{Methodology}

\subsection{Description of the statistical method}

Our aim is to see if the MOC can be estimated from simulated SSH and bottom pressure data from POCM output. Obtaining SSH is straightforward as it is output directly by the model. Bottom pressure, $p_{H}$, is obtained from:

$$
p_{H} \cong g \rho_{0} \zeta+g \int_{-H}^{0} \rho d z+p_{a}
$$

where $\zeta$ is SSH and $p_{a}$ is the atmospheric pressure. We use an average of four grid points for SSH and bottom pressure. Thus our bottom pressure data ( $\sim 100 \mathrm{~km}$ resolution) do not simulate the current GRACE satellite observations $(\sim 400 \mathrm{~km}$ resolution), but a future higher resolution mission instead.

Rather than use complex non-linear fitting procedures, such as neural networks or support vector machines (Hastie et al., 2003), we use a linear model. Our statistical model is given by:

$\operatorname{MOC}_{i}=\sum_{j=1}^{p} \alpha_{j} X_{i j}+\varepsilon_{i}$

where $M O C_{i}$ is the value of the MOC at the $i$ th timestep, $\alpha_{j}$ are coefficients corresponding to the linear predictors $X_{i j}(j=1, p)$, and $\varepsilon_{i}$ is an error term such that:

$\varepsilon_{i} \sim N\left(0, \sigma^{2}\right)$ and $E\left(\varepsilon_{i} \varepsilon_{j}\right)=0, i \neq j$

In other words, the error terms belong to a Normal distribution, $N$, with zero mean and standard deviation, $\sigma$; and the error terms are assumed to be independent of each other; i.e. the expectation value, $E$, of cross-correlations of different error terms is 0 .

The variables to be used as predictors in Eq. (3) need to be determined. Two sets of predictors are used: (1) a "geostrophic" set comprising SSH and bottom pressure values at either end $\left(79^{\circ} \mathrm{W}\right.$ and $\left.15^{\circ} \mathrm{W}\right)$ of the $26^{\circ} \mathrm{N}$ basin transect, and also at one point in the middle $\left(45^{\circ} \mathrm{W}\right.$; see Fig. 1); and (2) a "gyre" set comprising the first three empirical orthogonal functions (EOFs) for both SSH anomaly and bottom pressure anomaly (BPA) over the whole region of Fig. 1, as well as the subregions north and south of $26^{\circ} \mathrm{N}$. The rationale for the former set, i.e. (1), is clear. For the latter set, we exploit the suggestion by Häkkinen and Rhines (2004) that EOFs provide a measure of the gyre strength. Using EOFs north and south of $26^{\circ} \mathrm{N}$, as well as for the whole basin, allows us to distinguish the subpolar and subtropical gyres, albeit in a crude way. Equivalently, we may regard $26^{\circ} \mathrm{N}$ as the line of zero windstress curl, to a rough first approximation. Note that, like most ocean general circulation models, POCM conserves volume rather than mass $($ McDougall et al., 2002). In order to reduce the effect of any change in mass that may influence our results, we detrended SSH and BP locally (i.e., gridpoint by gridpoint).

In the statistical model we allow interaction between the various SSH terms and between the various BPA terms. However, for simplicity, we do not allow interactions between the SSH and BPA terms. Similarly, we do not allow interactions between the geostrophic terms and the gyre terms, or between the north, south or total gyre terms. Häkkinen and Rhines (2004) investigated the possible role of the North Atlantic Oscillation (NAO) in the strength of the MOC. Therefore, we also include an NAO index in the model.

Our model notation in Eq. (5) follows that of Wilkinson and Rogers (1973). Thus, "*” includes the interaction terms whilst "+" does not. Therefore, $\mathrm{A} * \mathrm{~B}+\mathrm{C}$, for example, means the terms $A+B+A \cdot B+C$; and $A * B * C$ indicates $\mathrm{A}+\mathrm{B}+\mathrm{C}+\mathrm{A} \cdot \mathrm{B}+\mathrm{A} \cdot \mathrm{C}+\mathrm{B} \cdot \mathrm{C}+\mathrm{A} \cdot \mathrm{B} . \mathrm{C}$. Our initial model is:

$$
\begin{gathered}
\text { MOC }=\text { Constant }+ \text { NAO } \\
\text { +Wssh } * \text { Mssh } * \text { Essh }+ \text { Wbpa } * \text { Mbpa } * \text { Ebpa } \\
+ \text { Bssh_1 } * \text { Bssh_2 } * \text { Bssh_3 + Bbpa_1 } * \text { Bbpa_2 } * \text { Bbpa_3 }(5) \\
+ \text { Nssh_1 } * \text { Nssh_2 } * \text { Nssh_3 + Nbpa_1 } * \text { Nbpa_2 } * \text { Nbpa_3 } \\
+ \text { Sssh_1 } * \text { Sssh_2 } * \text { Sssh_3 }+ \text { Sbpa_1 } * \text { Sbpa_2 } * \text { Sbpa_3 }
\end{gathered}
$$

where $s s h$ is sea surface height anomaly, bpa is bottom pressure anomaly, the prefixes $W, M$, and $E$ refer to the west, middle and east of the $26^{\circ} \mathrm{N}$ transect, respectively. The number at the end of the term denotes the $x$ th EOF. The prefix $B$ means the EOF covers the whole basin, $N$ is north of $26^{\circ} \mathrm{N}$ and $S$ is south of $26^{\circ} \mathrm{N}$. A location map showing the region of interest is given in Fig. 1. The results are presented in Sect. 4.

\subsection{EOF analysis}

As explained above, to obtain the linear predictors needed for Eq. (3) we require an EOF analysis of the two POCM datasets. These are sea surface height anomaly and bottom pressure anomaly. In both cases, "anomaly" simply means calculated with respect to the respective time-mean of the model variable over the POCM run from January 1979 to December 1998, inclusive.

The EOF principal components (i.e. the time series associated with each EOF) are used as inputs for the linear regression model. We calculate EOFs of SSH anomaly for the complete North Atlantic basin using POCM output. We repeat for the area north of $26^{\circ} \mathrm{N}$ and also the area south of $26^{\circ} \mathrm{N}$. There is a secular trend in SSH anomaly principal component mode 1 (not shown), indicative of model drift. We address this below. 

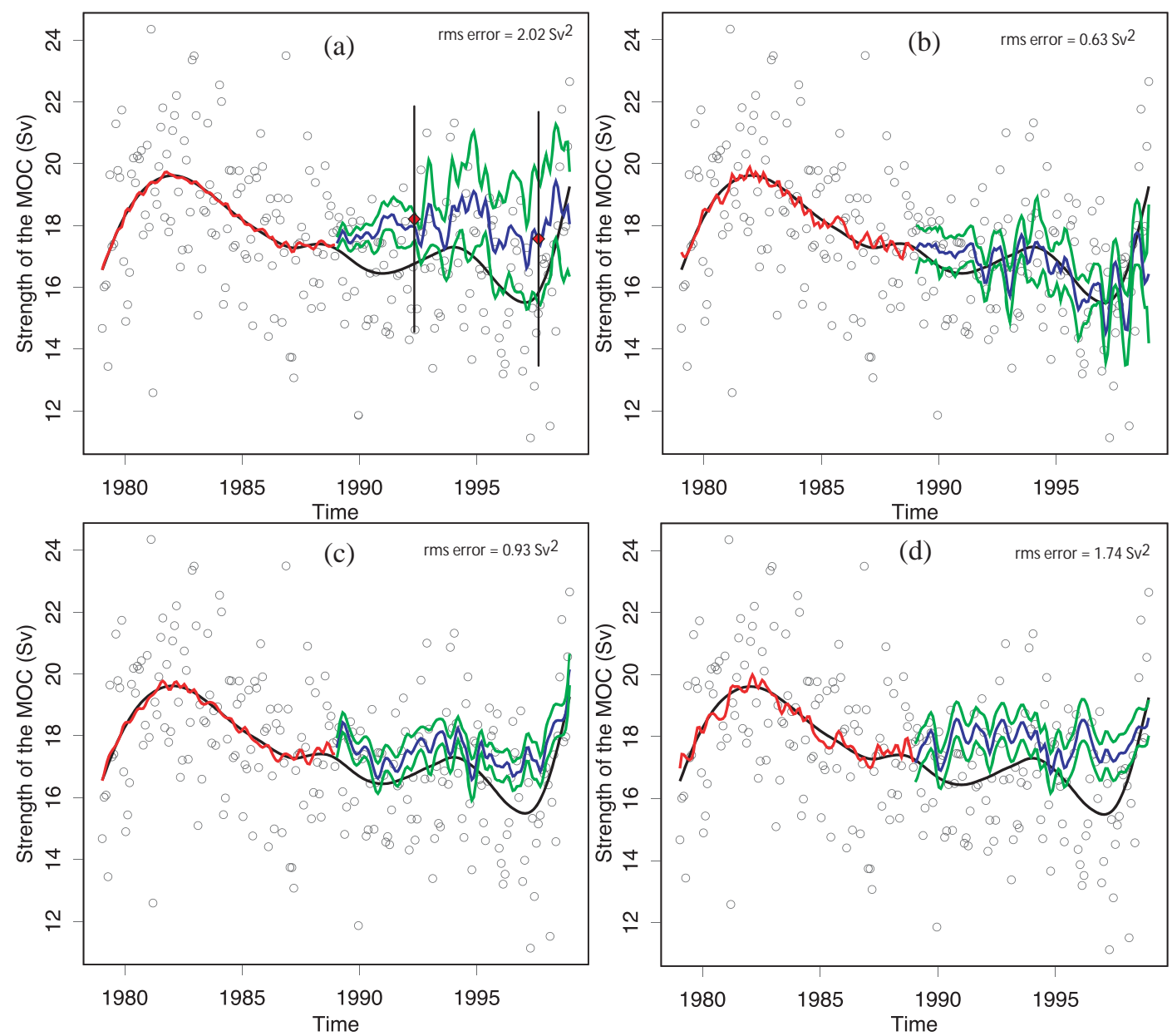

Fig. 2. The strength of the meridional overturning circulation in $\mathrm{Sv}$ at $26^{\circ} \mathrm{N}$ in POCM (open black circles are monthly averages; black line is smoothed MOC: see text for details). Linear model fit (red line) for the training data, and predictions (blue line) with $95 \%$ standard errors of the prediction (green line) for (a) the simplest regression model; (b) using smoothed and partially detrended inputs for the model; (c) adding satellite-equivalent noise to the inputs; and (d) using smoothed and detrended SSHA only. The diamonds in (a) represent actual observations, with the vertical lines representing their respective error bars (Marsh et al., 2005).

\section{Results}

Figure 2a shows the monthly strength of the MOC in Sv over the years 1979-1998. There is strong month-to-month variability. Our primary interest is in the long-term variation of the MOC, with most interest focusing on early warning of any imminent shutdown in the thermohaline circulation, rather than inter-month variation; therefore these MOC values are smoothed appropriately. We apply a simple spline smoother (smooth.spline in the R language (R Development Core Team, 2004)). The smoothed MOC is shown as the solid black line in Fig. 2. The long-term behaviour of the MOC is apparent: after an initial rise, the MOC strength falls almost linearly until 1997 when it recovers close to its earlier maximum strength of $20 \mathrm{~Sv}$. The reasons for this variability are as yet unknown.

We now fit the statistical model described in Sect. 3 to the data shown in Fig. 2. We use a standard F-test for the linear model (Venables and Ripley, 2002) to see which terms are significant. Note that we do not fit the terms sequentially; we simply fit the most complex model described in Sect. 3. The input variables for the model are smoothed using the spline smoother. The statistical model explains $93.5 \%$ of the variability prior to smoothing the inputs, and $98 \%$ following smoothing. In none of our fits is the NAO significant. This is consistent with the finding of Häkkinen and Rhines (2004) that the NAO is not a significant factor in the subpolar gyre weakening observed in the 1990s.

To test the strength of this model, we use the first half of the data as a training set to predict the MOC for the second half of the data. Using Eq. (5), the resulting fit explains $99 \%$ of the variability in the half of the data used for the fitting, but does not give a good prediction of the second half of the 
data (Fig. 2a). The mean square error of this prediction is $2.02 \mathrm{~Sv}^{2}$. We believe this relatively poor prediction arises from drift in the model output, even though model output data had been previously detrended locally (i.e., gridpoint by gridpoint). Earlier, we mentioned that POCM conserves volume rather than mass. It is possible for the model to gain or lose mass, which seems to have happened here. This likely affects the density structure of the ocean, influencing both the SSH and bottom pressure. In addition, this study only extracted a part of the Atlantic Ocean region from the global POCM dataset. Volume is not necessarily conserved in this subregion: thus, for example, a net loss of volume in the Atlantic Ocean will be compensated by a net gain somewhere else in the global ocean. Because volume is not conserved in the studied subregion there will be model drift, namely a trend in SSH. This is seen in the trend in the 1st EOF of SSH. Therefore, to correct for this model drift, in what follows we only use EOFs 2 to 4 for SSH: all terms involving the first EOF of SSH are removed. The mean square error of the prediction is now much improved to just $0.63 \mathrm{~Sv}^{2}$ (Fig. 2b).

We also simulated the effect of random errors in the satellite data. It is well known that the typical rms precision and accuracy of TOPEX/POSEIDON altimetry is $\sim 2 \mathrm{~cm}$. When we add $2 \mathrm{~cm}$ of noise to the detrended SSH model inputs, noise on the BPA data has very little effect on the error in the transport estimate. The results, using $0.02 \mathrm{mb}$ of noise for bottom pressure (a realistic value for future space gravity missions) are shown in Fig. 2c. The mean square error for this prediction is $0.93 \mathrm{~Sv}^{2}$. Intriguingly, the noise on the BPA data makes little difference whereas the noise on SSH has a large effect. The reason for this can be seen from Eq. (6) where we have removed the non-significant terms.

$$
\begin{aligned}
& M O C=\text { Constant }+\mathrm{Wssh}_{s}+\mathrm{Nssh}_{-} 3_{s}+\mathrm{Nssh}_{-} 4_{s} \\
& + \text { Bssh_2 } 2_{s} \text {.Bssh_ } 4_{s}+\text { Nssh_ } 2{ }_{s} \text {.Nssh_ } 3_{s}+\text { Sssh_ } 2{ }_{s} \text {.Sssh_3 } 3_{s} \\
& +\mathrm{Sssh}_{-} 3_{s} \cdot \mathrm{Sssh}_{-} 4_{s}+\mathrm{W} \operatorname{ssh}_{s} . \mathrm{Essh}_{s}+\mathrm{Wssh}_{s} \cdot \mathrm{Mssh}_{s} \cdot \mathrm{Essh}_{s} \\
& + \text { Bbpa } 2_{s}+\text { Bbpa } 33_{s}+\text { Sbpa }_{-} 1_{s}+\text { Bbpa }_{-} 1_{s} \text {. Bbpa } 2_{s} \\
& + \text { Bbpa_ } 2_{s} \text {. Bbpa_ } 3_{s}+\mathrm{Nbpa}_{-} 1_{s} \text {.Nbpa_ } 2_{s}+\text { Sbpa_ }_{s} . \text { Sbpa } 33_{s} \\
& + \text { Bbpa } \_1_{s} \text {. Bbpa } 2_{s} . \text { Bbpa } 3_{s}+\text { Wbpa }_{s} \text {. Ebpa }{ }_{s}
\end{aligned}
$$

where the subscript "s" refers to a simple spline smoother applied to the parameters.

Equation 6 shows that the only significant BPA variables are the large scale EOFs. The noise on individual measurements do not affect these (white noise is taken up by the higher order EOFs). However, if we were to add geographically correlated noise, as might be produced from a real satellite system, these would modify our results. The simulation of such errors is complex and is not considered in this paper.

Intriguingly, detrending the data before calculating the EOFs gives a worse prediction than detrending the EOFs themselves. In the former case we remove a separate trend for each grid point. This is probably removing relevant local information. On the other hand, working with the detrended EOFs tends to remove the large-scale trends that we expect to be caused by non-conservation of mass. This model, which has the best predictive skill (as measured by the lowest mean square error of $0.63 \mathrm{~Sv}^{2}$ ), is that shown in Fig. $2 b$.

To test whether the model can produce the same result without bottom pressure, the model was run using only SSH terms and used to predict the MOC for the second half of the data. The results can be seen in Fig. 2d. The mean square error is $1.74 \mathrm{~Sv}^{2}$. Thus omitting the bottom pressure terms gives a significantly worse prediction (compare with Fig. 2b).

\section{Discussion and future work}

Our study suggests that it is possible to monitor the meridional overturning circulation (MOC) using a combination of sea surface height and bottom pressure measurements from space. The eventual aim of this work is an early warning system for possible collapse of the North Atlantic thermohaline circulation. The considerable month-to-month variability means that we need to extract carefully the trend from the signal; otherwise many false alarms would be triggered.

The linear regression method explains $98 \%$ of the variability in the smoothed MOC when the inputs are smoothed. In fitting the regression we assumed that the residuals were uncorrelated. This is true for the unsmoothed data but the smoothing adds correlation and non-white residual noise. This noise has a rather complex structure and our attempts to model it using ARMA noise models have so far been unsuccessful. However, the successful prediction of the second, unfitted, half of the data shows that our model is robust, although the estimated errors are likely too low.

We have used the Parallel Ocean Climate Model (POCM) in this paper. It would clearly be useful to test the proposed method on other models also, such as OCCAM (Webb, 1996), HYCOM (Chassignet et al., 2003) or HadCM3 (Gordon et al., 2000), and also by exploiting high-resolution gravity data from space, probably from a follow-up GRACE mission. Once the MOC monitoring array near $26^{\circ} \mathrm{N}$ has been fully operational for some time we hope to compare it with our satellite-based method. Such a test will only be useful once a sufficiently long time series becomes available: perhaps $\sim 10$ years, as suggested by our prediction testing. We intend to repeat our studies at additional latitudes to test whether our methodology can be applied to monitor the MOC at locations other than that of the RAPID array, thus complementing and extending the array's capability.

Acknowledgements. We gratefully acknowledge useful suggestions and feedback from colleagues at NOCS, especially J. Hirschi and B. Sinha, and from the reviewers. This work was initially funded under the Rapid Climate Change thematic programme of the UK's Natural Environment Research Council.

Edited by: D. Stevens 


\section{References}

Bryden, H. L., Longworth, H. R., and Cunningham, S. A.: Slowing of the Atlantic meridional overturning circulation at $25^{\circ} \mathrm{N}$, Nature, 438, 655-657, 2005.

Chassignet, E. P., Smith, L. T., Halliwell, G. R., and Bleck, R.: North Atlantic simulation with the HYbrid Coordinate Ocean Model (HYCOM): Impact of the vertical coordinate choice, reference density, and thermobaricity, J. Phys. Oceanogr., 33, 2504 2526, 2003.

Gordon, C., Cooper, C., Senior, C. A. , Banks, H.T., Gregory, J. M., Johns, T. C., Mitchell, J. F. B., and Wood, R. A.: The simulation of SST, sea ice extents and ocean heat transports in a version of the Hadley Centre coupled model without flux adjustments, Clim. Dyn., 16, 147-168, 2000.

Gregory, J. M., K. W. Dixon, R. J. Stouffer, A. J. Weaver, E. Driesschaert, M. Eby, T. Fichefet, H. Hasumi, A. Hu, J. H. Jungclaus, I. V. Kamenkovich, A. Levermann, M. Montoya, S. Murakami, S. Nawrath, A. Oka, A. P. Sokolov, and R. B. Thorpe: A model intercomparison of changes in the Atlantic thermohaline circulation in response to increasing atmospheric $\mathrm{CO}_{2}$ concentration, Geophys. Res. Lett., 32, L12703, doi:10.1029/2005GL023209, 2005.

Häkkinen, S.: Variability in sea surface height: A qualitative measure for the meridional overturning in the North Atlantic, J. Geophys. Res., 106, 13 837-13 848, 2001.

Häkkinen, S. and Rhines, P. B.: Decline of Subpolar North Atlantic Circulation During the 1990s, Science, 304, 555-559, 2004.

Hastie, T., Tibshirani, R., and Friedman, J.: The Elements of Statistical Learning: Data Mining, Inference and Prediction. Springer, 2003.

Hirschi, J, Baehr, J., Marotzke, J., Stark, J., Cunningham, S., and Beismann, J.-O.: A monitoring design for the Atlantic Meridional Overturning Circulation, Geophys. Res. Lett., 30(7), 1413, doi:10.1029/2002GL016776, 2003.

Killworth, P. D., Stainforth, D., Webb, D. J., and Patterson, S. M.: The development of a free-surface Bryan-Cox-Semtner ocean model, J. Phys. Oceangr., 21, 1333-1348, 1991.

Levermann, A., Griesel, A., Hofmann, M., Montoya, M., and Rahmstorf, S.: Dynamic sea level changes following changes in the thermohaline circulation, Clim. Dyn., 24, 347-354, 2005.

McDougall, T. J., Greatbatch, R. J., and Lu, Y.: On conservation Equations in Oceanography: How Accurate are Boussinesq Ocean Models?, J. Phys. Oceangr., 32, 1574-1584, 2002.

Marsh, R., de Cuevas, B. A., Coward, A. C., Bryden, H. L., and Alvarez, M.: Thermohaline circulation at three key sections in the North Atlantic over 1985-2002, Geophys. Res. Lett., 32, L10604, doi:10.1029/2004GL022281, 2005.

Matano, R. P., Beier, E. J., Strub, P. T., and Tokmakian, R.: Largescale forcing of the Agulhas variability: The seasonal cycle, J. Phys. Oceangr., 32, 1228-1241, 2002.
R Development Core Team: R: A language and environment for statistical computing, R Foundation for Statistical Computing, Vienna, Austria, http://www.R-project.org, 2004.

Rahmstorf, S.: Thermohaline Ocean Circulation, in Encyclopedia of Quaternary Sciences, edited by: Elias, S. A., Amsterdam, Elsevier, 2006.

Rahmstorf, S. and Ganopolski, A.: Long-term global warming scenarios computed with an efficient coupled climate model, Clim. Change, 43, 353-367, 1999.

Semtner, A. J. and Chervin, R. M.: Ocean general circulation from a global eddy-resolving model, J. Geophys. Res., 97, 5493-5550, 1992.

Stammer D., Tokmakian, R., Semtner, A., and Wunsch, C.: How well does a $1 / 4^{\circ}$ global circulation model simulate large-scale oceanic observations? J. Geophys. Res., 101(C10), 25779 $25811,1996$.

Stocker, T. F., Knutti, R., and Plattner, G.-K.: The Future of the Thermohaline Circulation - A Perspective in The Oceans and Rapid Climate Change: Past, Present and Future, edited by: Barron, E. J. and Seidov, D., American Geophysical Union. Geophysical Monograph., 126, 277-293, 2001.

Tapley, B. D., Chambers, D. P., Bettadpur, S., and Ries, J. C.: Large scale ocean circulation from the GRACE GGM01 Geoid, Geophys. Res. Lett., 30(22), 2163, doi:10.1029/2003GL018622, 2003.

Tapley B. D., Bettadpur, S., Watkins, M., and Reigber, C.: The gravity recovery and climate experiment: Mission overview and early results, Geophys. Res. Lett. 31, L09607, doi:10.1029/2004GL019920, 2004a.

Tapley, B. D., Bettadpur, S., Ries, J. C., Thompson, P. F., and Watkins, M. M.: GRACE Measurements of Mass Variability in the Earth System, Science, 305, 503-505, 2004b.

Tokmakian, R.: Comparisons of time series from two global models with tide-gauge data, Geophys. Res. Lett., 23(25), 3759-3762, 1996.

Tokmakian, R. and Challenor, P. G.: On the joint estimation of model and satellite sea surface height anomaly errors, Ocean Modell., 1, 39-52, 1999.

Venables, W. N. and Ripley, B. D.: Modern Applied Statistics with S, Springer, New York, 2002.

Wahr, J. and Molenaar, M.: Time variability of the Earth's gravity field: Hydrological and oceanic effects and their possible detection using GRACE, J. Geophys. Res., 103(B12), 30 205-30 229, 1998.

Webb, D. J.: An ocean model code for array processor computers, Comput. Geosci., 22, 569-578, 1996.

Wilkinson, G. N. and Rogers, C. E.: Symbolic description of factorial models for analysis of variance, Appl. Statist., 22, 392-399, 1973.

Wood, R. A., Keen, A. B., Mitchell, J. F. B., and Gregory, J. M.: Changing spatial structure of the thermohaline circulation in response to atmospheric $\mathrm{CO}_{2}$ forcing in a climate model, Nature, 399, 572-575, 1999. 